\title{
RESQUEBRAJAMIENTOS DE LA TEORÍA DEL CONSENSO SOCIAL CON EL GOLPE DE ESTADO EN ARGENTINA: LOS CASOS DE BANCARIAS/OS Y ESTUDIANTES EN LA PROVINCIA DE MENDOZA (1975)
}

\author{
Violeta Ayles Tortolini* \\ Instituto de Investigaciones en Estudios de Género (FFyL-UBA) - CONICET
}

Este artículo ofrece una reconstrucción histórica de dos casos paradigmáticos en la política represiva previa al golpe de Estado de 1976 en Mendoza, que tuvieron como objeto a militantes del Partido Revolucionario de los Trabajadores: el primer secuestro y desaparición momentánea del trabajador bancario Pablo Marín y el asesinato de la estudiante Gladys Beatriz Sabatino y secuestro, desaparición y asesinato del estudiante Amadeo Sánchez Andía. La reconstrucción de estos hechos permite visibilizar la reacción de sus compañeras y compañeros de trabajo y de estudios. Las luchas fueron masivas y combativas y en el primer caso lograron la soltura de Marín. La hipótesis del artículo pone en discusión la idea de que el golpe de Estado fue recibido con alivio y sin resistencia por el grueso de la sociedad. Para el trabajo se acudió al análisis de fuentes periodísticas, judiciales y orales.

PALABRAS CLAVE: Golpe de Estado, Mendoza, Argentina, historia local, Partido Revolucionario de los Trabajadores

Enviado: $01 / 11 / 2020$

Aceptado: 12/01/2021

*atvioleta@hotmail.com 


\title{
CRACKING OF THE SOCIAL CONSENSUS THEORY WITH THE COUP D'ÉTAT IN ARGENTINA: THE CASES OF BANK WORKERS AND STUDENTS IN THE PROVINCE OF MENDOZA (1975)
}

\author{
Violeta Ayles Tortolini* \\ Instituto de Investigaciones en Estudios de Género (FFyL-UBA) - CONICET
}

This article offers a historical reconstruction of two paradigmatic cases in the repressive policy prior to the 1976 coup in Mendoza, which targeted members of the Revolutionary Workers Party: the first kidnapping and momentary disappearance of bank worker Pablo Marín and the murder of student Gladys Beatriz Sabatino and kidnapping, disappearance and murder of student Amadeo Sánchez Andía. The reconstruction of the events shows the massive combative reaction of the victims work and study colleagues which in the case of Marín resulted in his release. The hypothesis of the article calls into question the idea that the coup was received with relief and without resistance by the bulk of society. For the work, the analysis of journalistic, judicial and oral sources was used.

KEY WORDS: Coup d'état, Mendoza, Argentina, Local history, Revolutionary Wor kers Party

Enviado: $01 / 11 / 2020$

Aceptado: $12 / 01 / 2021$

*atvioleta@hotmail.com 


\section{INTRODUCCIÓN}

Las décadas de 1960 y 1970 en Argentina han sido objeto de una multiplicidad de estudios del ámbito académico, historiográfico y también del periodismo de investigación. A riesgo de recaer en esquematismos, se puede afirmar que hay tres grandes perspectivas interpretativas desde las que se mira ese pasado reciente. Por un lado, la teoría de la guerra sucia, cuyos orígenes remiten a la contemporaneidad de los hechos, puesto que su autoría corresponde a las Fuerzas Armadas (FF.AA.). Esta teoría construyó la noción de enemigo interno, recurriendo al vago concepto de subversión, dentro de cuyos márgenes podía ubicarse a cualquier activista. La teoría de la guerra sucia carga responsabilidades sobre la llamada subversión y legitima la intervención política de las FF.AA. y sus prácticas de secuestro, tortura y desaparición como necesarias e inevitables para ponerle límite a este grupo que ponía en cuestión los valores de la sociedad argentina, la tradición cristiana y occidental, la patria y la familia. En otro orden, se encuentra la teoría de los dos demonios, cuyo origen remite al prólogo del informe elaborado por la Comisión Nacional sobre la Desaparición de Personas (CONADEP) en 1985 bajo el título Nunca Más. De manera sintética, se puede decir que esta teoría describe aquellas décadas a través del enfrentamiento entre dos extremos violentos, uno de izquierda y otro de derecha. En tanto, el grueso de la sociedad padecía de manera pasiva las consecuencias de esta confrontación, lo que la constituía en víctima inocente. Una tercera perspectiva interpretativa afinca en el pensamiento crítico y la historia desde abajo. Aunque no todos los trabajos que integran esta perspectiva lo hacen, gran parte de ellos acuden al marxismo como enfoque teórico. Se trata de estudios que parten de comprender el conflicto como factor intrínseco de las sociedades, por lo que apuestan a la reconstrucción histórica de experiencias concretas en aras de visibilizar sujetos ampliamente borrados, como la clase trabajadora o las mujeres y disidencias. Por ello, aquí no se habla de subversión ni de extremismo de izquierda, sino que se analizan las motivaciones que empujan a los sectores subalternos a luchar -incluso con métodos violentos- por transformar la realidad existente. En tanto, la dictadura es entendida como una forma coercitiva a que acuden los sectores dominantes al ver en peligro su lugar en el orden social o al intentar imponer un nuevo orden, todavía más desigual, para el que necesitan que no existan resistencias.

Como se advirtió, se trata de una exposición esquemática a los fines de presentar a grandes rasgos las características generales de las principales interpretaciones del pasado reciente argentino. Al interior de cada enfoque 
teórico hay matices y polémicas. E incluso entre ellos a veces los márgenes son porosos y algunos estudios toman elementos de una y otra teoría.

Si bien la memoria del Nunca más remite a la teoría de los dos demonios expresada en el informe de la CONADEP, los enfoques afincados en ella lo exceden, abordando un abanico más amplio de sentidos. Principalmente, parten de una defensa de la democracia entendida en términos de democracia liberal representativa. Como contracara, impugnan la violencia insurreccional como antítesis no sólo de la democracia, sino hasta de la política. Esta perspectiva, impulsada como política de la memoria por el Estado durante el gobierno del presidente Raúl Alfonsín (1983-1989), acumuló diversos consensos y se constituyó en una memoria hegemónica debido a su sentido político de legitimación de la transición democrática que libera a la sociedad civil y al Estado democrático de culpas y responsabilidades. Además, el éxito en la acogida de esta memoria por amplios sectores sociales e intelectuales obedece a su autorreferencia como defensora de valores como el respeto por la democracia y los Derechos Humanos ${ }^{1}$.

Entre los diversos sentidos que abarca la predominante memoria del Nunca más se halla la idea de que el golpe de Estado efectuado por las Fuerzas Armadas el 24 de marzo de 1976 fue recibido con alivio por el grueso de la sociedad que ya estaba harta de los enfrentamientos y el caos y expectante de que los militares restablecieran el orden. En ese argumento se puede visualizar un punto de contacto entre la memoria del Nunca más y la teoría de la guerra sucia. Por ejemplo, Calveiro afirma: "La sociedad estaba harta $\mathrm{y}$, en particular la clase media, clamaba por recuperar algún orden. Los militares estaban dispuestos a salvar una vez más al país, que se dejaba rescatar, decidido a cerrar los ojos con tal de recuperar la tranquilidad y la prosperidad perdidas muchos años atrás"2. En idéntico sentido, en una obra que pretende analizar el comportamiento de la gente común -que sería la que no participa en política-, Carassai señala: “... las clases medias ajenas a la lucha política [...] no lamentaron la caída de Isabel Perón ${ }^{3}$, cuyo destino miraban desde hacía tiempo con indiferencia, y recibieron con alivio la llegada de los militares"

1. F. LeVín (2009).

2. P. Calveiro (2005), 49.

3. Esposa y vicepresidenta de Juan Domingo Perón, asumió la presidencia ante el fallecimiento de este, el 1 de julio de 1974, y fue derrocada con el golpe militar.

4. S. Carassai (2013), 292. 
Varias de las obras dedicadas a la historia del Partido Revolucionario de los Trabajadores-Ejército Revolucionario del Pueblo (PRT-ERP) -organización en la que militaban las personas cuyos asesinatos y desapariciones se reconstruyen en este artículo- afincan en esta interpretación. Con matices y variantes entre sí, afirman que el PRT-ERP estaba destinado a la marginación desde sus orígenes por haber persistido en una estrategia militar en detrimento de la política, contribuyendo torpemente a la inclinación de la balanza a favor de la dictadura, recorriendo un camino que conducía a una derrota inevitable y aplastante. En ese sentido, cuestionan su estrategia de guerra civil revolucionaria caracterizándola de modo genérico como militarista, equiparan política con participación electoral y afirman su creciente aislamiento de las masas ${ }^{5}$.

Otro tanto sucede con la historiografía hegemónica en Mendoza, que en su afán de garantizar la imagen de la provincia como tranquila, despolitizada y carente de conflicto social, reproduce el discurso de los militares y ubica a las y los militantes revolucionarios de la provincia en el rol de infiltrados foráneos, profesionales a sueldo que se aprovecharon de algún descontento genuino pero coyuntural ${ }^{6}$. Mientras que otros estudios locales, que buscaron ubicarse dentro de los márgenes de la nueva historia, replican la descripción de Mendoza en función de su "tradicional moderación"” y de la década del '70 como una "etapa intoxicada de ideología", ubicando una vez más a las organizaciones revolucionarias como algo externo, implantado, que se hizo presente en Mendoza a través de la violencia.

El presente artículo se ubica en la perspectiva de la historia desde abajo y ofrece nuevas evidencias que aportan al resquebrajamiento de la teoría del consenso social con el golpe de Estado. Lo hace desde una escala local y articulando las categorías de clase y género para interrogar al pasado reciente. Se trata de la reconstrucción empírica y detallada de dos casos que resultan bisagra en la política represiva en Mendoza previa al golpe y que no han sido explorados por la historiografía local. Se identifican elementos que refieren a saltos en calidad en la política represiva local y a la aplicación de prácticas que se tornarán sistemáticas luego del 24 de marzo de 1976. Se presta atención a la reacción de sus compañeras/os de trabajo

5. M. Seonne (1991); I. Antognazzi (1993); A. Longoni (2000); J. Santucho (2004); V. Carnovale (2011); A. Oberti (2015).

6. A. Cueto; A. Romano y P. Sacchero (1994).

7. P. Lacoste (2004), 341.

8. A. Micale (2004), 369. 
en el primer caso y de estudios en el segundo, a fin de observar si se trata de un comportamiento pasivo, cómplice, aliviado o resistente y combativo.

\section{PABLO MARÍN: PRIMERA DESAPARICIÓN TRANSITORIA - ENERO DE 1975}

Antes de pasar a la reconstrucción del hecho represivo es preciso realizar un sucinto repaso de la situación previa del sector bancario que permita la contextualización a las/os lectoras/es. En los años '70 las/os trabajadoras/es bancarias/os de Mendoza desarrollaron una extensa experiencia de organización sindical, a la vez que una cantidad considerable de ellas/os participaron de organizaciones políticas y también político-militares (entre ellas del PRT-ERP). Sus medidas de lucha fueron amplias y combativas y al calor de esa experiencia, entre mediados de 1973 y principios de 1974, constituyeron Comisiones Gremiales Internas (CGI) en todos los bancos, estatales y privados, de la provincia. La mayoría era conducida por frentes de corrientes de izquierda y del peronismo de izquierda ${ }^{9}$. Esta experiencia también posibilitó la realización de un frente electoral para la conducción provincial de la Asociación Bancaria. Si bien este frente era conducido por el peronismo, la izquierda logró ocupar lugares: Pablo Marín y José "Pepe" Lozano (ambos militantes del PRT-ERP) fueron elegidos Secretario de Prensa y de Acción Social, respectivamente. Pero ese frente único se fue resquebrajando durante 1974 a raíz de las presiones del peronismo de derecha que imponía la verticalidad del movimiento peronista y un contundente macartismo. La ruptura se dio entre la Asociación Bancaria por un lado (a excepción de Lozano y Marín ${ }^{10}$ ) y las CGI por el otro, donde la izquierda tenía mayor peso. Es elocuente en ese sentido el cántico que rezaba "Duro, duro, duro, que se vayan los zurdos"11, levantado por la derecha peronista en una de las asambleas de trabajadoras/es bancarias/os.

Según la historiadora Rodríguez Agüero, pionera en los estudios sobre represión en Mendoza, los sectores de la clase trabajadora más golpeados por los comandos parapoliciales fueron los mismos que en los últimos años emprendieron las luchas más radicalizadas: docentes, estatales y bancarias/

9. L. Rodríguez Agüero; N. Baraldo y P. Lozano (2016).

10. Marín renunció a su cargo en abril de 1974 por diferencias con la conducción, mientras Lozano fue expulsado poco después por plegarse a un paro impulsado por un plenario de trabajadoras/es y no por la conducción.

11. Mendoza (11/04/1974), 7. 
os, constituyéndose estos últimos en blanco predilecto de la represión previa a la dictadura ${ }^{12}$. La militancia combativa de las CGI concentró la atención de la patronal y de las fuerzas represivas. En su declaración en el IV Juicio por delitos de Lesa Humanidad en Mendoza (2014), el exdelegado bancario Hermes Ocaña relató que, en el Banco de Previsión Social, se había formado un grupo de seguridad bancaria integrado por policías del D-2 ${ }^{13}$ que se dedicaban a hacer inteligencia dentro del banco ${ }^{14}$.

La persecución al activismo bancario incluyó atentados con bombas en casas y autos de delegados y la detención reiterada de sus dirigentes. Cada acción de amedrentamiento recibía por respuesta de las trabajadoras y trabajadores asambleas, comunicados de repudio, paros y movilizaciones. Estas medidas fueron protagonizadas por las CGI, mientras que la conducción del gremio no sólo no accionaba por los reclamos económicos propios del sector, sino que dejaba a sus activistas desprotegidas/os frente a la creciente cantidad de atentados y persecuciones.

Pablo Marín era trabajador del Banco de Previsión Social, amigo de Luis "Pelado" Ocaña, con quien ingresaron al PRT-ERP cuando este se constituyó en Mendoza, a mediados de $1973^{15}$. Aportaron a la organización su sólido trabajo de base en el sector bancario. Como ya quedó dicho, Marín fue secretario de Prensa de la Bancaria y renunció a su cargo el 6 de abril de 1974 en el contexto de las disputas entre las CGI y el Secretariado para posicionarse del lado de las bases. También fue el responsable de la célula perretista $^{16}$ de bancarios de Mendoza.

Según el relato de Ocaña, a Marín lo detuvieron porque lo encontraron haciendo una pintada sobre una pared de la Universidad Tecnológica Nacional (UTN). Generalmente, estas actividades de propaganda eran organizadas con determinados recaudos de seguridad que imponía la creciente política represiva. Se organizaban grupos de por lo menos tres militantes garantizando que mientras una/o pintaba las/os otras/os chequearan que no se

12. L. Rodríguez Agüero (2013).

13. Departamento 2 de Informaciones de la Policía de Mendoza. Allí funcionó uno de los principales centros clandestinos de detención, tortura y exterminio de la provincia. En la actualidad, en parte de sus instalaciones funciona el Espacio para la Memoria y los Derechos Humanos.

14. L. Rodríguez Agüero; N. Baraldo y P. Lozano (2016).

15. Sobre la constitución del PRT-ERP en la provincia y el lugar ocupado por estos trabajadores bancarios en esa experiencia, recientemente publiqué el artículo Orígenes del PRT-ERP en Mendoza.

16. Perretistas, perros o erpianos se les decía que a quienes militaban en el PRT-ERP. 
acercara nadie. Pero en esta ocasión, ya habían hecho una pintada y Pablo, el "Flaco" para Ocaña, estaba volviendo a su casa: "venía de vuelta con el aerosol y encuentra esa pared blanca y le sacudió de una punta hasta la otra. Cuando está llegando a la última, está haciendo la última estrella lo cazó un cana ${ }^{17}$. Y lo caza con el aerosol en la mano y los dedos llenos de pintura" ${ }^{18}$. Efectivamente, cuando la noticia apareció en los diarios -trece días después- se informó que había sido detenido el 12 de enero de 1975 por "pegar carteles de índole política en inmediaciones de la UTN Facultad Regional Mendoza [y que fue] acusado de haber pintado leyendas callejeras subversivas (violación de la Ley 20.840 - Ley de Seguridad del Estado)"19. Mientras que otro diario local señalaba que la causa obedecía a "presuntas actividades extremistas" 20 .

Continuando con el relato de Ocaña, Alfredo "el Gordo" Guevara fue el abogado que asumió la defensa de Marín ${ }^{21}$. Juntos crearon la versión que se diría ante el juez: Pablo pasaba caminando por allí y vio a una persona pintando la pared y que tiraba un aerosol al piso, él lo levantó para mirarlo y en ese momento llegó la policía. El día que lo llevaron desde la Penitenciaría Provincial hasta Tribunales Federales, sus compañeras/os bancarias/ os se concentraron en la puerta del juzgado para acompañarlo y exigir su libertad: "habíamos llevado medio banco ahí a la puerta. No se usaba eso, pero era una de las primeras veces que pasaba" ${ }^{22}$. La estrategia de Guevara funcionó y absolvieron a Marín, pero debían trasladarlo nuevamente a la Penitenciaría para que firmara allí el acta de su soltura. Entonces, cuenta Ocaña que decidieron ampliar la convocatoria e ir a recibirlo cuando saliera de la Penitenciaría para celebrar su liberación:

Y le digo al Petiso Galván: 'Loco, llamate al Regional, al Crédito de Cuyo y vamos y lo traemos en andas, a los putos gritos'. Estábamos agrandados porque traerlo al Flaco en andas era un triunfo. [...] La cosa es que va el Petiso y se acarrea como 250 monos a la puerta de la cárcel. Y vamos (me

17. Así se llama a la policía en la jerga popular.

18. Entrevista a Luis "Pelado" Ocaña (08/04 y 15/04/2011).

19. Los Andes (25/01/1975), 12.

20. Mendoza (25/01/1975), 7.

21. Entre los/as principales abogados/as que se dedicaron a la defensa de presas/os políticas/os en la época estuvieron Alfredo Guevara y Haydeé Clorinda Fernández del Río (peronistas), Fuad Toum (integrante de la organización maoísta Vanguardia Comunista) y el comunista Ángel Bustelo.

22. Entrevista a Luis "Pelado" Ocaña (08/04 y 15/04/2011). 
acuerdo que tenía un Citroën) con el Gordo Guevara y nos plantamos ahí a esperar que saliera y llevárnoslo tocando bocina, haciendo un quilombo $\mathrm{y}$ hacer una asamblea en el Banco cuando llegara el Flaco. Y no salía y no salía y no salía y no salió. De repente, entra un Falcon a la cana, al interior de la cana y sale echando puta, y el Gordo dice: 'Ahí va huevón, en el baúl'. Y lo seguimos de atrás. Y, en efecto, la Federal entró, lo sacó y se lo llevó a la Federal y lo estaban recontra cagando a palos, le dieron una paliza que ni te cuento. Cuando el Gordo dice: 'Bueno vamos, vamos todos huevón, tráetelos' y nos fuimos todos. Éramos... ¿qué sé yo? Ya llegábamos como a los 300 en la puerta de la calle Perú. Yo no me olvido más ${ }^{23}$.

Este hecho es significativo porque luego se va a repetir en otros casos en los que, al momento de la liberación legal, las/os activistas eran secuestradas/os de manera ilegal para ser desaparecidas/os. En este caso, luego de haber sido detenido por la policía, Pablo Marín fue encerrado en la Penitenciaría Provincial. El día que un juez federal ordenó su liberación, la policía Federal ingresó a la Penitenciaría y se lo llevó ilegalmente a sus dependencias, donde fue sometido a torturas. Su abogado ingresó a la sede de la Policía Federal -en Perú y Emilio Civit de Ciudad- y constató que allí estaba Marín y lo habían golpeado. Mientras tanto, las/os trabajadoras/es bancarias/os se mantenían concentradas/os en la puerta y Ocaña les transmitía en arenga lo que el Dr. Guevara le informaba. Fue justamente gracias a la solidaridad de sus compañeras/os que se logró su real liberación.

El hecho de la detención de Marín recién fue noticia en los diarios cuando se convirtió en secuestro y la Comisión Interna del Banco de Previsión Social (BPS) hizo conferencia de prensa haciendo la denuncia. La reconstrucción periodística de lo sucedido el viernes 24 de enero, cuando Marín fue secuestrado de la Penitenciaría, coincide por entero con la información brindada por Ocaña. Sólo agrega que, ante la considerable demora para que saliera de la Penitenciaría, fue la esposa de Marín la que ingresó en dos oportunidades para preguntar por él. En la primera, le respondieron que la demora obedecía a trámites de rutina. En la segunda, luego del ingreso y egreso a toda velocidad del Ford Falcon con tres varones de civil, le dijeron que su esposo ya había sido liberado y se había retirado del establecimiento. Frente a ello, no sólo se movilizaron hasta la Policía Federal, sino que las/os trabajadoras/es se declararon en estado de asamblea permanente, hicieron conferencia de prensa, enviaron telegramas a la

\section{Ibidem.}


presidenta de la Nación y al ministro del Interior y solicitaron entrevista con el ministro de Gobierno de Mendoza, mientras los abogados Alfredo Guevara y Fuad Toum presentaban habeas corpus por Marín. Su liberación recién se produjo al día siguiente, sábado 25, cuando el juez Agüero hizo lugar al habeas corpus, se reconoció que la Policía Federal había detenido a Marín para su identificación y se ordenó su inmediata liberación. Finalmente, el lunes 27 hubo una masiva asamblea en el BPS, con la concurrencia de trabajadoras/es de otros bancos, donde habló Marín y denunció haber sido sometido a torturas ${ }^{24}$.

En cuanto al PRT-ERP, el secuestro producido a fines de enero recién fue reflejado en una nota a principios de marzo bajo el título Mendoza: respuesta a la represión. Además de la crónica de los hechos, se hace énfasis en el recrudecimiento de la política represiva y en cuál debe ser la respuesta popular. En ese sentido, la nota relata que en la asamblea:

Un miembro de la Comisión Gremial Interna del Banco de Previsión Social, señaló que la liberación del compañero Marín fue lograda gracias a la unidad y solidaridad manifestada por los compañeros bancarios y por toda la prensa de Mendoza. Al compañero Marín se lo veía con el rostro demacrado y debía hacer visibles esfuerzos físicos por caminar y sentarse.

La detención del compañero, uno más de las decenas de detenciones que se producen diariamente en todo el país, nos muestra una vez más el carácter crecientemente represivo y fascistoide que va adquiriendo este gobierno.

Su liberación, gracias a la movilización combativa de sus compañeros de trabajo, fue una concesión que se vió [sic] obligada a otorgar el gobierno. ¡He aquí una respuesta justa al accionar represivo! ${ }^{25}$.

Luego de esa situación, Marín continuó viviendo bajo persecución. Según su compañero, en una ocasión Santuccione le dijo "Te voy a pegar un tiro en medio de la cabeza" 26 . Frente a ello, resolvieron colectivamente que Marín debía abandonar la provincia. En 1975, se fue a Buenos Aires bajo la identidad falsa de Miguel Farías y allí fue parte de la dirección de la regional Capital Federal del PRT-ERP ${ }^{27}$. En 1977 se fue con un grupo

24. Los Andes (25, 26 y 28/01/1975) y Mendoza (25 y 28/01/1975).

25. El Combatiente (03/03/1975), s.p.

26. El brigadier Julio César Santuccione era el Jefe de la Policía de Mendoza y cabeza de los grupos parapoliciales Comando Anticomunista Mendoza (CAM) y Comando Moralizador Pío XII.

27. Entrevista a Abel Bohoslavsky (18/11/2009). 
de compañeras/os a Brasil a pedir refugio a través del ACNUR, pero decidieron regresar y Marín continuó militando. Fue secuestrado al asistir a una cita "envenenada" según la jerga militante de la época. Es decir, que estaba organizada por las fuerzas represivas. Es posible que haya pasado por el centro clandestino de detención El Vesubio e integra la lista de desaparecidos/as desde el 6 de noviembre de $1977^{28}$.

\section{AMADEO Y GLADYS: PRIMER DESAPARECIDO EN MENDOZA... ¿PRIMERA ASESINADA? - MAYO Y JUNIO DE 1975}

Por la noche del 28 de mayo de 1975, tres perretistas abordaron un colectivo de la empresa Colta en la terminal de Mendoza con destino a Córdoba. Se trataba de Amadeo Zenón Sánchez Andía, Gladys Beatriz Sabatino y Aníbal Carlos Testa Farías. Amadeo, alias "Bigote" o Lucas, tenía 31 años según su esposa (aunque el diario informa que tenía 27), era peruano y vivía en la provincia desde 1969. Trabajaba como empleado administrativo y cursaba cuarto año en la Escuela de Comunicación Colectiva, donde además era secretario general del Centro de Estudiantes. Estaba casado con una compañera de estudios y militancia, Monona, con quien esperaban una beba. Él había participado activamente en el Mendozazo y tenía una formación marxista. Cuando se comenzó a construir el PRT-ERP en Mendoza, a mediados de junio de 1973, junto con Monona fueron de las primeras personas en sumarse. Gladys, alias "Kity", tenía 24 años y era estudiante de cuarto año de la carrera de Medicina de la Universidad Nacional de Cuyo (UNCuyo). No se pudo acceder a datos que indiquen sus responsabilidades militantes, aunque Monona la ubica desempeñando tareas en el frente estudiantil también. Para el responsable político de la regional, "era un cuadro la mina esa, talentosísima, estaba a punto de recibirse" 29. En el caso de Aníbal Testa, se trataba de un militante cordobés que había viajado hasta Mendoza para buscar a Gladys y Amadeo.

El motivo del viaje que realizaban no está del todo claro. Según Monona, Aníbal Testa había venido a reclutarlos para ir a una escuela de cuadros en Córdoba como paso previo a que se incorporaran a la Compañía de Monte en Tucumán ${ }^{30}$. Con esta versión también coincide Rafael

28. Entrevista a Luis "Pelado" Ocaña (08/04 y 15/04/2011).

29. Entrevista a Santiago Ferreyra (18/07/2012).

30. Entrevista a Mirtha "Monona" Ramírez (26/02 y 16/04/2011). 
Bonino, quien era compañero de célula partidaria de Amadeo y Monona $^{31}$. En cambio, para quien se desempeñaba como responsable de la Regional Mendoza del PRT-ERP en ese momento, Amadeo y Gladys se dirigían a Buenos Aires junto con Testa para participar de un plenario estudiantil ${ }^{32}$. Según el ex integrante de la Policía Federal, Carmelo Cirella Paredes, en una entrevista ofrecida para el documental 7746 Legajo CONADEP, Amadeo era militante de la organización uruguaya Tupamaros y cumplía la función de correo, transportando información de distintas organizaciones del Cono Sur. Eso es lo que estaría haciendo en el momento del viaje ${ }^{33}$. Esta versión es falsa, lo que será demostrado más adelante.

Pero el viaje no llegó a destino porque, siendo las $0.40 \mathrm{hs}$ de la madrugada del jueves 29 de mayo, el colectivo chocó de frente con un camión acoplado que transportaba aceite comestible para la empresa Sinatra. El accidente fue en el cruce de Ruta Panamericana y Ruta Nacional 7, a la altura del departamento de La Paz, en el Este provincial. La situación caótica fue reflejada con notas centrales en ambos diarios locales. El primer día ya había diez muertas/os. Decenas de personas quedaron atrapadas entre hierros y los primeros auxilios ofrecidos por las vecinas y vecinos de La Paz fueron fundamentales ${ }^{34}$. En uno de los diarios se observa una foto de Aníbal Testa y su propio testimonio, en el que relata que viajaba con un gamulán cubriéndole la cabeza y que cree que eso lo salvó ya que lo protegió de los golpes. Iba durmiendo cuando se produjo el accidente y al despertarse tenía encima una mujer muerta. Ayudó a rescatar heridos y por un tiempo perdió la memoria, pero por la tarde la recobró. Entrevistado en una camilla del Hospital Regional de San Martín, con su cabeza vendada, Aníbal Testa le dijo al periodista que esperaría allí hasta que viniera a buscarlo su esposa desde Córdoba ${ }^{35}$.

En la entrevista realizada a Santiago Ferreyra, cuenta que se enteró del accidente a la mañana siguiente, a través de la radio. Inmediatamente fue a la Terminal de ómnibus y confirmó que se trataba del colectivo donde viajaban sus compañeros/a. Entonces, se comunicó con otro militante que tenía un Fiat 600, Rafael Bonino, y le pidió que lo llevara hasta el hospital. Ferreyra había comprado los pasajes y sabía que tenían los últimos

31. Entrevista a Rafael Bonino (10/09/2020).

32. Entrevista a Santiago Ferreyra (18/07/2012).

33. R. Sepúlveda (2006).

34. Los Andes (30/05/1975); Mendoza (30 y 31/05/1975).

35. Los Andes (30/05/1975). 
asientos, cumpliendo con una medida de seguridad que obedecía a que, en caso de que se encontraran con un operativo policial y estos subieran al colectivo, tuvieran tiempo para reaccionar. Como el choque había sido de frente, Santiago tenía la expectativa de encontrarlos/a con vida. Al llegar al hospital, observaron que la zona estaba saturada de presencia policial. Santiago le pidió a Rafael que lo esperara en una esquina e ingresó como si fuera el familiar de un paciente. A través de la ventanilla de una puerta identificó a sus compañeros:

Entonces voy, me acerco y le digo: "Bigote ¿qué te ha pasado?” Y me agarra así, fuerte, y me dice: “¿Quién soy? ¿Quién soy?” "Pará, tranquilizate un poquito. Tranquilo que te va a doler la cabeza si no. Yo te voy a decir despacito". Y entonces lo miro a Aníbal y me dice: "No recuerda nada". Y yo le digo: "Negro, vestite cagando que nos vamos ya”. Y entonces él sigue: “¿Quién soy? ¿Quién soy?" Pero hablaba fuerte. Y le digo: "Pará, calmate hermano". Yo de ahí no me lo podía llevar, porque no puedo llevarme a alguien en contra de su voluntad, alguien que se ponga a gritar en el camino, porque estaba lleno de canas. Entonces le pregunto por la Gladys al Aníbal y me dice: "Ya está bien, la trasladaron al Hospital Central". O sea, los que tenían alguna contusión fuerte estaban ahí y no los movían. Y los que no tenían ningún golpe fuerte, los trasladaron y los dejaron internados en el Hospital Central. Yo le muevo el pelo, le sale la sangre, era una sola mancha de sangre... Y salimos de ahí, le presto mi campera porque estaba con pijama, no sé con qué ropa, pero era ropa manchada. Y de vuelta pasamos como invisibles. Y cuando salimos de ahí me dice una enfermera: “¿Qué hace usted acá señor?" “Tengo autorización del director, nos retiramos porque está en perfectas condiciones". "Ah, bueno" ${ }^{36}$.

En otra entrevista, Bonino confirmó el grueso de esta versión, aunque con algunas diferencias. Por ejemplo, en su relato ambos ingresaron al Hospital y directamente no pudieron ver a Amadeo porque ya tenía una consigna policial en la puerta. Por ello sólo se pudieron llevar a Testa y quedaron en organizar un nuevo rescate ${ }^{37}$. Con los matices sobre cómo fue el rescate, lo cierto es que lograron retirar a Aníbal Testa, mientras Amadeo Sánchez Andía quedó en el Hospital. Santiago, Aníbal y Rafael volvieron a Mendoza y en unos días se enteraron del secuestro de Amadeo por los medios. Pero antes de este hecho, sucedió otro que todavía no ha

36. Entrevista a Santiago Ferreyra (18/07/2012).

37. Entrevista a Rafael Bonino (10/09/2020). 
sido develado: la muerte de Gladys Sabatino. Ella había sido trasladada al Hospital Central que se encuentra en la Capital de Mendoza. Ferreyra recuerda que, al sacar a Aníbal del Hospital de San Martín, este le dijo que la compañera se encontraba en perfectas condiciones, que no tenía ni un corte y que le había dado aliento diciéndole que se quedaran tranquilos porque ella arreglaría todo. Pero, curiosamente, en el Hospital falleciós ${ }^{38}$. Efectivamente, uno de los diarios indica su nombre como una de las diez víctimas fatales del accidente. Señala que la mayoría se produjo en el acto o en el inmediato traslado, mientras que el último deceso correspondió a Gladys Sabatino, "una joven estudiante de Medicina, a las 16.45 en el Central" 39 . Una prima de Gladys estuvo ese día cuidándola en el Hospital Central, donde se encontraba perfectamente estable. Por la tarde, un médico le solicitó que fuera a comprar un remedio mientras le hacían el último control antes de darle el alta. Al regresar, media hora después, le informaron que se había descompensado y había fallecido ${ }^{40}$. Esta versión fue reiterada por su sobrino, Luis Eduardo Lenzano, en su declaración en el marco del VI Juicio en Mendoza, en agosto de $2017^{41}$. La familia de Gladys no supo cómo actuar en ese momento y ni siquiera cuenta con un legajo en CONADEP ya que no realizó la denuncia, pero para quienes integran los Organismos de Derechos Humanos y para los/as militantes del PRT-ERP sobrevivientes, Gladys fue asesinada en el Hospital Central.

Es que la policía detectó la identidad política de Amadeo en menos de 24hs. Santiago Ferreyra hizo mucho esfuerzo por desentrañar cómo habían llegado a saberlo. Por un lado, reconoció un error propio. Amadeo debía transportar un informe para la reunión a la que se dirigía, entonces Santiago había hecho algo que denominaba "mariconera" y que se trataba de una cartera que fabricaban ellos mismos en un taller que habían montado: "era un sobre negro de vinil, con una división y una trabita"42. Se colocaba un lienzo en una máquina de escribir, como si fuera una hoja, y allí se volcaba el informe. Luego, este lienzo iba cosido dentro de la cartera por lo que el informe pasaba inadvertido ante un operativo. El error cometido fue que, al entregárselo a Amadeo, allí mismo colocó los tres pasajes. Pero, además, después de hacerle varias preguntas a Aníbal, se encontró con que

38. Entrevista a Santiago Ferreyra (18/07/2012).

39. Los Andes (30/05/1975), 7.

40. Diario UNO (14-05-2012).

41. https://juiciosmendoza6.wordpress.com/tag/gladys-beatriz-sabatino/

42. Entrevista a Santiago Ferreyra (18/07/2012). 
este le había dado el libro La Orquesta Roja para que se lo guardara en la cartera. Allí estaban el libro, el informe y los tres pasajes juntos. La conclusión de Santiago es que la policía encontró en la cartera, el libro y los tres pasajes y luego deben haber desarmado la cartera y hallado el informe que los identificaba como militantes del PRT-ERP. Por eso secuestraron a Amadeo y mataron a Gladys, quedando con vida sólo Aníbal porque lo pudieron rescatar a tiempo ${ }^{43}$. Esta conclusión probablemente sea cierta, ya que la noche del 30 de mayo (el día posterior al accidente) realizaron un allanamiento en el departamento donde vivían Amadeo y Monona y a él le colocaron custodia policial en la sala del hospital.

El hermano de Monona, Joaquín Ramírez, declaró en el juicio en agosto 2017 que luego del accidente fue a visitar a su cuñado al Hospital de San Martín y vio que tenía una custodia policial y que se encontraba solo en una habitación. En esa ocasión, Amadeo estaba consciente y le preguntó por la chica que iba en el colectivo con él. Además, le pidió que le llevara un pijama. Cuando Joaquín regresó al Hospital con el pijama ya no le dejaron ver a su cuñado y debió dejarlo en la Mesa de entradas ${ }^{44}$.

El sábado 7 de junio se conocía la noticia sobre el secuestro de Amadeo y la aparición de su cuerpo en Canota. Según los diarios locales, fue secuestrado el viernes 6 , a las $2.10 \mathrm{hs}$ de la madrugada, de la sala donde se hallaba internado en el Hospital de San Martín. Seis hombres armados, disfrazados con máscaras y pelucas, apartaron a su hermano, Juan, que lo cuidaba y obligaron a guardar silencio a otro paciente y su acompañante ${ }^{45}$. Se llevaron a Amadeo de su camilla mientras se quejaba por el dolor de las heridas del accidente y lo subieron a una ambulancia. Los diarios también dan cuenta de que su casa había sido allanada y que permanecía con custodia policial, aunque no se contaba con información oficial respecto de los motivos de esta. Curiosamente, la custodia policial que nunca se despegaba de la sala, no se encontraba en el lugar al momento del secuestro. A las $16 \mathrm{hs}$ hubo una comunicación telefónica con dos comisarías dando indicaciones sobre cómo localizar el cuerpo, que fue hallado con la

43. Al regresar a Mendoza, Aníbal Testa salió de la provincia en avión. Luego, fue secuestrado el 11 de septiembre de 1976 en Buenos Aires e integra la lista de desaparecidos.

44. Cfr. https://juiciosmendoza6.wordpress.com/tag/gladys-beatriz-sabatino

45. Esto fue confirmado por Juan Régulo Sánchez Andía en su declaración en el juicio en junio de 2017. Además, agregó que él fue trasladado bajo maltratos a una comisaría de la que fue liberado al día siguiente, y al volver al hospital fue a la habitación que ocupaba Amadeo y encontró un llavero de la Policía Federal con la inscripción "Juan Ramón Falcón". Cfr. https://juiciosmendoza6.wordpress.com/tag/gladys-beatriz-sabatino/ 
cara desfigurada, desnudo, con marcas de golpes y cuatro tiros de un arma calibre 14 (uno en el ojo). Además, con brea le habían pintado una "T" en la frente, cruces en los ojos, círculos en los glúteos y en el tórax hasta la mitad de la espalda le escribieron la leyenda "Por traidor monto"46. En varias ocasiones el diario deja ver que se sospechaba que se trataba de un operativo guerrillero. Ya en el subtítulo afirmaba "Los extremistas usaban peluca y parecían foráneos" ${ }^{\prime 47}$, cuando el adjetivo de extremista era utilizado por la prensa local para referirse a las/os integrantes de organizaciones revolucionarias. En idéntico sentido titulaba el diario Mendoza, aun teniendo en cuenta las condiciones en que fue hallado el cadáver y publicando una pavorosa foto del mismo: "Operativo extremista en el Este. Fue copado el hospital de San Martín y se secuestró a uno de sus pacientes" ${ }^{48}$. Este diario afirma que la policía descubrió que Amadeo era Tupamaro y que hacía de "correo", a la vez que señala que viajaba con Gladys Sabatino. Ambas notas dan cuenta de que, según la policía, a Amadeo lo llevaron hasta el monumento a Canota en auto, lo hicieron descender y lo golpearon. Luego lo obligaron a correr y cuando se encontraba en el lecho del río seco le dispararon. Allí cayó al piso y lo remataron con otros disparos, entre ellos el que tenía en un ojo.

Dos días después, Mendoza informaba que según fuentes policiales Amadeo y Gladys viajaban a Córdoba para participar de "un congreso que celebrarían distintos grupos extremistas" 49 . Afirmaban que se había encontrado un bolsillo secreto en el abrigo de ella, entre la tela y el forro, donde había documentos políticos. Los mismos que hallaron en el gamulán de Sánchez Andía, por lo que presumían que iban a distinto destino o que llevaban los informes repetidos por si les sucedía algo a alguno de los dos. No sólo eso, el diario también daba cuenta de que se sabía que iban con una tercera persona, que todavía no había sido identificada ${ }^{50}$. Es evidente que la inteligencia había atado los cabos y había conectado a Gladys con Amadeo. La pregunta para la que sólo hay una respuesta conjetural es si esto sucedió (o no) antes de la muerte de Gladys. En este trabajo se considera que sí.

46. Los Andes (07/06/1975), 11. Monto se les decía a los/as militantes de Montoneros, una organización político-militar del peronismo de izquierda.

47. Ibidem.

48. Mendoza (07/06/1975), 8 .

49. Mendoza (09/06/1975), 12.

50. Ibidem. 
En su declaración en el juicio, Joaquín Ramírez relató que recorrió más de diez comisarías para dar con el cuerpo de su cuñado, que finalmente encontró en la morgue del Hospital Miliar. Las autoridades no le permitieron velarlo. Debían proceder directamente con el entierro. Ramírez relató que el cortejo fúnebre contó solo con dos autos. En uno iba él y en el otro iba Juan, el hermano de Amadeo. Y aún así fueron custodiados por patrulleros policiales ${ }^{51}$.

Para Santiago Ferreyra, el secuestro de Amadeo Sánchez Andía fue obra de Tradición, Familia y Propiedad $^{52}$ porque en su cuerpo había una cruz gamada: "Es una cruz que tiene doble palo, viste, cruzada, la cruz que usaba Tradición" 53 . En cambio, en el documental 7746-Legajo CONADEP, dirigido por el periodista Rodrigo Sepúlveda, el ex suboficial de la Delegación Mendoza de la Policía Federal, Carmelo Cirella, afirma que en el secuestro de Amadeo participaron Oscar Fenocchio, Rodolfo Cardello, Ricardo Aleks, José Luis Mirotta y Marcelo León. Todos eran miembros de la Policía Federal. Según Cirella, Amadeo fue llevado unas horas a la delegación de la Policía Federal -la misma donde había sido torturado Pablo Marín unos meses antes- a efectos de interrogarlo y luego lo trasladaron a Canota ${ }^{54}$.

De todos modos, la interpretación de Santiago y la confesión de Cirella no necesariamente resultan contradictorias. De lo poco que se sabe del funcionamiento de las organizaciones parapoliciales en Mendoza, principalmente gracias a los trabajos de Rodríguez Agüero, todas tenían algún vínculo con la policía. De hecho, el articulador del Comando Anticomunista Mendoza (CAM) y del Comando Moralizador Pío XII fue el jefe de la policía local, Julio César Santuccione. Es probable que no haya sido precisamente el grupo Tradición, Familia y Propiedad, pero sí algún otro comando de los que operaban, ya que todos exhibían un fuerte componente conservador, católico y moralista. Las fronteras entre las fuerzas policiales

51. Cfr. https://juiciosmendoza6.wordpress.com/tag/gladys-beatriz-sabatino/

52. Tradición Familia y Propiedad era un movimiento católico, ultraconservador, de Argentina y de Chile. Su objetivo era detener lo que denominaban la infiltración marxista tanto en la iglesia como en la sociedad. Cuando ganó la Unidad Popular en Chile (1970), varios de sus miembros se trasladaron a Argentina y aquí continuaron accionando en contra del presidente Salvador Allende. Cfr. L. Rodríguez Agüero y A. Paredes (2012).

53. Entrevista a Santiago Ferreyra (18/07/2012).

54. Esta declaración autoincriminatoria había sido ofrecida por Cirella ante la CONADEP en 1984. Luego, fue repetida para la filmación del documental en 2006. Pero en 2007, al ser citado a declarar ante la Justicia Federal, el represor alegó que había mentido en las dos ocasiones anteriores. 
y los comandos parapoliciales eran porosas y permeables, lo que facilitaba la combinación de acciones legales y extralegales para la represión de las organizaciones revolucionarias. Lo cierto es que se trata del primer secuestro, desaparición, tortura y asesinato en Mendoza, diez meses antes del golpe de Estado. Inauguró un modo de operar que se repetiría: el abandono del cadáver -con signos de haber sido sometido a prácticas de tormento- en lugares como Canota, Papagallos, etc. Una de las singularidades de este caso, fue el intento de hacerlo pasar como un ajuste de cuenta entre organizaciones guerrilleras a través de la leyenda "por traidor, Monto". Intención que no tuvo ni un mínimo eco entre quienes militaban en estas organizaciones en Mendoza, que bien sabían que las autoras eran las fuerzas represivas.

Para sus compañeras/os de militancia y de estudio, el hecho no pasó inadvertido, ni fue recibido con pasividad. Durante semanas las/os estudiantes de la Escuela de Comunicación Colectiva hicieron acciones y publicaron declaraciones de repudio y exigencia de justicia. De hecho, el mismo día que los diarios informaban sobre el secuestro y asesinato de Amadeo, también debían dar cuenta de la respuesta estudiantil. Los Andes recibió a un grupo de estudiantes en la redacción y reprodujo lo que ellas/ os contaron ${ }^{55}$, mientras Mendoza trascribió su comunicado:

La totalidad del estudiantado de Comunicación Colectiva, al tomar conocimiento del rapto y muerte a mansalva del compañero miembro del Centro de Estudiantes, Amadeo Sánchez, se autoconvocó en asamblea general, desoyendo las expresas disposiciones del director del instituto. En dicha asamblea se resolvió manifestar públicamente el repudio del conjunto del estudiantado por la muerte del compañero Sánchez. Además, solicitar una adhesión de toda la opinión pública a través de sus sectores representativos políticos, gremiales y estudiantiles, y exigir ante los poderes del Estado, sean judiciales, parlamentarios o ejecutivos, del orden provincial y nacional, que se investiguen profundamente las circunstancias del hecho y descubrir sus autores.

Por otra parte, también comprometen a las autoridades policiales a que se expidan sobre el mismo, dado que Amadeo Sánchez era uno de los heridos del accidente ocurrido en La Paz y estaba internado en el hospital regional de San Martín con custodia policial, en calidad de detenido ${ }^{56}$.

Este comunicado no es un gesto menor, si se tiene en cuenta que se publica en momentos de creciente represión y atentados a nivel provincial

56. Mendoza $(07 / 06 / 1975), 8$. 
y en el país. Las/os estudiantes apuntaron directamente al corazón de la represión: la policía. Y lo hicieron incluso contra la prohibición de las autoridades de la Escuela. Además, ofrecieron otro dato: habían presentado un recurso de hábeas corpus ante el Juzgado Federal previo al secuestro de Amadeo y no recibieron respuesta. Este dato fue confirmado en la Audiencia 23 de la Megacausa, el 29 de junio de 2017, cuando el abogado Carlos Bula declaró que el Dr. Ángel Bustelo presentó un hábeas corpus para salvaguardar la vida de Amadeo, pero fue rechazado por la Justicia Federal ${ }^{57}$. Esto lo había hecho a pedido de su hermano, que les había dicho que luego del accidente Amadeo se encontraba detenido, que pertenecía a una agrupación guerrillera y que le habían encontrado alguna documentación que lo comprometía. Incluso, Bula relató que viajaron a visitar a Amadeo al Hospital de San Martín. Para verlo, debieron solicitar autorización en la comisaría. Luego de pasar la guardia policial de la puerta, pudieron hablar con Amadeo, que les dijo que había escuchado que alguien había dicho sobre él: "a este tipo hay que hacerle algo". Y frente a eso, Amadeo le dijo al abogado "Tengo temor de que me boleteen" 58 .

Vilma Rúpolo en ese momento era compañera de militancia y de estudios de Amadeo. Ella cuenta que apenas se enteraron del hecho hicieron unos afiches con su foto y una inscripción que decía "Han matado a Amadeo Sánchez, estudiante de Comunicación Colectiva" y con eso empapelaron la ciudad. "Estábamos como desesperados ¿viste? No, no podíamos creer lo que había pasado. Y eso nos movía mucho, la bronca que teníamos" 59 . Luego, también publicaron una revista con el nombre de Amadeo que repartían en la misma Escuela.

E1 9 de junio, las/os estudiantes de Comunicación y de otras facultades quisieron hacer un acto en la Escuela de Comunicación Colectiva, a pesar de que el director interventor de la misma, Edmundo Tomei, se lo prohibió. Aun así, izaron la bandera a media asta y dijeron palabras en conmemoración de Amadeo. Luego se enteraron de que Tomei había llamado a la policía y decidieron retirarse, pero en ese momento el director cerró las puertas con llave. Al lograr salir, las/os estudiantes se dirigieron a las redacciones de los diarios para denunciar el hecho y pedir una reunión con el ministro

57. La complicidad de la Justicia Federal con el aparato clandestino de secuestros ha sido denunciada en reiteradas ocasiones por los/as sobrevivientes del genocidio y cuatro jueces federales de Mendoza ya han sido condenados por ello.

58. Cfr. https://juiciosmendoza6.wordpress.com/tag/gladys-beatriz-sabatino/

59. Entrevista a Vilma Rúpolo (25/02/2011). 
de Educación y Cultura ${ }^{60}$. Al día siguiente, las/os estudiantes de la Escuela Superior de Arte hicieron la siguiente declaración: "Repudiamos el cobarde asesinato del estudiante de Comunicación Colectiva Amadeo Sánchez y expresamos nuestra total solidaridad con los compañeros de periodismo, constituyéndonos en estado de alerta" ${ }^{61}$. El nivel de presión fue tal que hasta la Intervención Federal en Mendoza tuvo que pronunciarse sobre el hecho. Elaboró un comunicado, a través de la Dirección de Prensa y Difusión, que se publicó en ambos diarios locales. En el mismo se repudiaba el hecho a la vez que se manifestaba la oposición a la violencia sin importar cuál fuera su origen y se convocaba "a la concordia argentina y a la paz, que son, sin duda, los caminos para la conciliación nacional" ${ }^{62}$. Los términos del comunicado oficial son elocuentes. Que lo hayan realizado no obedece a otro motivo que el nivel de presión popular sobre el asunto y lo atroz de un hecho que todavía no era cotidiano, como pasó a ser pocos meses después. De todos modos, no se expresó sobre la operatividad específica de los grupos parapoliciales e insistió con la idea de paz en momentos donde desde el mismo Estado se perpetraba el terror.

Las/os estudiantes de Comunicación continuaron en estado de alerta y publicaron una solicitada en la que exigían al ministro del Interior y a la intervención federal provincial que diera explicaciones sobre las circunstancias misteriosas que rodeaban al asesinato de Amadeo. Entre ellas: "Allanamiento y destrucción de muebles de su vivienda [...]; Custodia policial en el hospital regional de San Martín, luego de sufrir un tremendo accidente [...]; Dicha custodia estaba ausente el día del secuestro" ${ }^{3}$. Unos días más tarde, las/os estudiantes de Medicina comenzaban un paro por reivindicaciones propias de la carrera, pero en la nota que hacían pública manifestaban su repudio al asesinato de Sánchez Andía ${ }^{64}$.

Hubo otras víctimas en este hecho. Ante el viaje de Amadeo, Monona se había quedado en la casa de otro compañero del PRT-ERP y de la Escuela de Comunicación, Hernán Fierro, para no estar sola. Al día siguiente de la partida de Amadeo, fue un amigo que tenían en común a contarle a Hernán que habían allanado el departamento del "Negro". Se sorprendió al ver a Monona porque daba por hecho que la habían secuestrado en el

60. Los Andes (10/06/1975); Mendoza (11/06/1975).

61. Mendoza (11/06/1975), 5.

62. Los Andes (11/06/1975), 10.

63. Mendoza (12/06/1975), 4.

64. Mendoza (19/06/1975). 
allanamiento. Esa fue la forma en que Monona se enteró del accidente de su esposo y comenzó su propio calvario. Durante el allanamiento de su casa le robaron dinero y ropa. Ese mismo día, con ayuda de su amigo y compañero de militancia, Rafael Bonino, la llevaron a esconderse en una casa en Luján, le cortaron su largo cabello negro y la tiñeron de rubia. Monona cuenta que no la dejaban ir al hospital a ver a Amadeo por razones de seguridad, pero que “...dicen que él había preguntado por mí, cómo estaba yo, que no le mintieran. Porque él creía que todos le decían que estaba bien yo y él creía que le habían mentido, que me había llevado la policía o el ejército y no le querían decir" ${ }^{\prime 5}$.

En ese estado de angustia, embarazada, escondiéndose y sin poder ver a su marido herido, una mañana Monona escuchó en la radio que Amadeo había sido secuestrado por un comando de su propio partido:

Y estábamos re felices porque nosotros estábamos convencidos de que eran compañeros los que se lo habían llevado. A la tarde, estoy viendo la tele y dicen que han encontrado un cuerpo de una persona, de tantos años, así, que tenía un cartel que decía: "Por traidor monto". Y yo dije: "Es Amadeo"66.

Esa noche fueron Hernán Fierro y Rafael Bonino a confirmarle que se trataba de Amadeo, y en el Fiat 600 de Rafael la llevaron a la casa de su hermano en Tunuyán. Al día siguiente tomó un colectivo rumbo a General Alvear a la casa de sus padres. Aunque esta se encontraba vigilada, pudo ingresar gracias al enmascaramiento de su pelo corto y rubio. Allí quedó escondida por meses. Una tía le consiguió un médico amigo, de filiación peronista, que iba hasta la casa a hacer el seguimiento del embarazo. Monona recuerda con agradecimiento que la haya atendido gratis y que no la haya denunciado: "esos gestos en esa época eran tan importantes. Viste, porque era jugarse la vida ellos por alguien que, por ahí, en última instancia, no tenía nada que ver con ellos" ${ }^{67}$.

Esos meses estuvieron atravesados por el profundo terror que le inspiraba la idea de que pudieran matar a su beba y con la urgencia de decidir cómo iba a parir. Finalmente, a principios de diciembre de 1975, fue a tener a su beba -que lleva el nombre de Gladys Beatriz en honor a Sabatino- a un hospital a pocas cuadras de lo de sus padres. Según su recuerdo:

65. Entrevista a Mirtha "Monona" Ramírez (26/02 y 16/04/2011).

66. Ibidem.

67. Ibidem. 
Yo rompí bolsa un miércoles y Gladys nació el lunes de la semana siguiente. Yo tenía que ir a cesárea directo. A mí lo que no me torturaron, yo lo sufrí en esos días. Porque yo tenía contracciones cada un minuto que me volvían loca y no me hacían cesárea. El director del hospital era el tío de mi cuñada, la esposa de mi hermano, viste. Entonces, mi papá, ya pasados todos esos días, fue y lo amenazó de muerte y le dijo: "O le hacés cesárea a mi hija para que nazca el bebé o yo lo mato", le dijo mi papá. Entonces, me llevaron al quirófano.

\section{¿Por qué no te hacían la cesárea?}

Porque ellos querían que se muriera el bebé. Y que, si me podía morir yo mejor, viste. Entonces, bueno... No me llevaron al quirófano, le dijeron que me iban hacer cesárea, no me llevaron al quirófano, me llevaron a una sala de parto. Y ahí, el médico hizo esto con mi vagina (ruido de rajadura), me rajó así. Bueno, Gladys pesó 4 k. 400. Salió... es negra como mi negrita, viste. Salió morada, no respiraba. Decían: "Ha tragado meconio, no va a vivir". Y qué sé yo. Claro, si hace una semana que no tenía líquido, mi amor. Bueno, la llevan a neonatología. Al otro día a la mañana me vienen a buscar a la sala a mí y me dicen: "Andá a despedirte de la bebé porque no va a vivir. Tiene los pulmones tapados, el corazón agrandado, le han tocado el cerebro eee..." Yo estaba, no podía ni caminar, estaba medio obnubilada, no podía despedirme de mi bebé68.

La hija de Monona y Amadeo vivió y hoy es una mujer, pero esos días efectivamente fueron una tortura física y psicológica para ella. Un tormento que no acabó allí. A principios de 1976 la policía le hizo llegar una citación y se presentó en la comisaría donde la interrogaron sobre Amadeo. Al volver a su casa quemó una carpeta que le hacía a Gladys con historias y fotos de su papá. Por la noche, la VIII Brigada de Infantería irrumpió en su casa, allanó el lugar y le dijeron que agarrara frazada y cepillo de dientes porque la detenían. Con cinismo, el inspector le dijo: "Venga, yo le voy a enseñar cómo se hace la frazada para que vaya aprendiendo" ${ }^{69}$. La llevaron hasta la comisaría de Alvear, la cambiaron de móvil y la llevaron a la Regional Segunda de San Rafael. Allí fue sometida nuevamente a un interrogatorio. Finalmente, le hicieron firmar un acta y le dijeron que la dejaban en libertad. Cuando bajaba las escaleras, se encontró con su hermano y un abogado, porque él la había estado buscando por las comisarías de la zona. Según Monona, eso le salvó la vida, porque cuando se fueron vio que había un grupo de varones en la esquina, listos para secuestrarla. Luego de ese hecho, Monona fue asediada en reiteradas oportunidades por

68. Ibidem.

69. Ibidem. 
la policía, además de haber sido expulsada de la carrera de Comunicación (donde le negaron su legajo y los títulos intermedios que había obtenido) y de enfrentar múltiples obstáculos para conseguir trabajo.

A fines de julio de 1975, la prensa del ERP le dedicó una hoja al secuestro, tortura y asesinato de Amadeo. Bajo el título El adiós al compañero, además de relatar los hechos, se reproduce una carta escrita por Monona y la foto de Amadeo.

Querido compañero:

Hoy recién a una semana de tu trágica muerte, puedo tomar un lápiz para escribir algo sobre ti, pero me pregunto ¿es que hay algo que se pueda escribir sobre un revolucionario? ¿Se puede expresar en un simple papel algo más de los que las masas han expresado y sentido?, esa impotencia, ese dolor retenido, ese tragarse las lágrimas, y apretar los puños y sentir más que nunca la convicción de que nuestra causa es la justa.

Compañero mío, siempre supimos que esto podía pasar y estábamos preparados para afrontarlo, pero así como llorábamos cuando leíamos en la Estrella Roja la muerte de algún compañero, así lloro hoy al recordar tu cuerpo masacrado por la violencia asesina de los esbirros fascistas, pero tu muerte no fue en vano Negro, tu ejemplo revolucionario, el recuerdo de tu vida dedicada a la militancia, tu amor por el Partido, por el pueblo, por la causa, será el ejemplo que nos guiará a los que nos formamos a tu lado, por el camino luminoso de la revolución proletaria. Pero hay algo más compañero, algo que quedó como testimonio inviolable de tu paso por la vida y este ser que late en mi seno, este ser que se prepara para reemplazarte en la lucha. Compañero, podría decir mucho más de ti, pero creo que no hay nada más elocuente que el fruto de tu obra y solo me resta decirte que fuiste revolucionario hasta en el momento de tu muerte. No pudieron sacarte una palabra, preferiste entregar tu vida a cambio de la vida de nuestro pueblo, por eso como tu decías y escribías en las paredes: ¡A VENCER O MORIR POR LA ARGENTINA, Compañero querido! Tu compañera ${ }^{70}$

\section{CONCLUSIONES}

Luego de una exhaustiva reconstrucción empírica, el análisis de ambos casos permite extraer una serie de conclusiones. En cuanto al secuestro de Pablo Marín es preciso reflexionar en torno a la combinación de las dos identidades que se sintetizaban en su persona: la de dirigente de masas de

70. Estrella Roja (28/07/1975), 4.

(C) Baetica. Estudios Historia Moderna y Contemporánea, 40, 2020, 427-455. Facultad de Filosofía y Letras, Universidad de Málaga. Departamento de Historia Moderna y Contemporánea 
una organización sindical combativa de trabajadoras/es y la de militante de una organización guerrillera. Pablo Marín era un dirigente, no sólo en su banco, el BPS, sino del gremio en general, y era una de las cabezas de un proceso de autoorganización y de lucha parido desde las bases que se tornaba masivo y combativo, al punto de enfrentarse con su propia conducción sindical. Uno de los objetivos principales de la represión fue destruir las organizaciones de la clase trabajadora, lo cual lo constituía en blanco predilecto. Pero, además, a Marín lo detienen realizando una pintada del ERP. Con lo cual, suponiendo que su identidad política hubiera escapado hasta ese momento a los servicios de inteligencia, en ese hecho ya quedaba explícita. Un elemento clave es la inauguración de una práctica que se volvería habitual con el correr del tiempo: el secuestro al momento de ser liberado de una detención legal. Por ello se lo señala como un caso en el que se observa un salto en calidad en la política represiva.

Otro aspecto para reflexionar respecto de este caso es la solidaridad de clase. El apoyo de sus compañeros/as de trabajo fue sostenido, aun cuando era de público conocimiento que la causa de la detención respondía a su militancia guerrillera. Se trata de una nueva evidencia que desmiente la noción falsa pero hegemónica que sostiene que las/os militantes revolucionarias/ os eran infiltrados en el pueblo, ajenos/as a su identidad y deseos. Las/os compañeras/os de trabajo y militancia gremial de Pablo Marín lo defendieron porque él era parte de su propia identidad, no una infiltración foránea. De hecho, la inmensa celeridad con la que lograron articular una respuesta tan contundente y efectiva en el momento del secuestro, consiguiendo la movilización inmediata de centenares de trabajadores/as junto con las acciones legales, da cuenta del elevado nivel de organización que sostenían.

En el segundo caso estudiado, la represión desatada a partir del accidente del colectivo presenta varios aspectos a tener en cuenta. Por un lado, la celeridad con que las fuerzas represivas lograron desentrañar la identidad militante de Amadeo Sánchez Andía y Gladys Beatriz Sabatino da cuenta de la gimnasia permanente en la tarea de inteligencia. Más allá de que la conexión se haya producido a través del hallazgo del informe en la cartera junto a los pasajes, como supone Santiago, o porque se encontraron los mismos informes en los abrigos de Amadeo y de Gladys, como afirmó la prensa, lo cierto es que recién iniciada la madrugada del 29 de mayo chocó el colectivo, en la tarde del mismo día se produjo el presunto asesinato de Gladys y por la noche se allanó la casa de Amadeo y Monona y se dispuso la custodia policial sobre el primero. Que Aníbal haya sobrevivido al episodio se debe exclusivamente a la celeridad con la que también actuaron sus compañeros. 
¿Qué sucedió con Gladys Sabatino en el Hospital Central? Todavía no ha podido ser demostrado. Pero la sospecha de sus familiares y compañeras/os respecto de que fue asesinada exhibe bases sólidas si se repasa cómo sucedieron los hechos desde el momento en que ella alentaba a sus compañeros a que estuvieran tranquilos y era trasladada sin ninguna complicación grave, hasta que repentinamente se descompensa y muere justo cuando no hay ningún testigo presente porque casualmente se le ha pedido a su acompañante que salga de la sala.

Ocho días después, el 6 de junio, se produce el secuestro de Amadeo. La participación de la Policía Federal en el mismo ofrece un hilo de continuidad con el secuestro de Pablo Marín realizado cinco meses atrás. Pero, además, deja ver la dialéctica fluida entre el accionar dentro de los marcos de la ley y por fuera de ella. Todavía faltaban diez meses para el golpe de Estado, pero los dispositivos genocidas ya estaban aceitados y en marcha en el marco del gobierno constitucional. Las prácticas que luego serían sistemáticas empezaban a ser ensayadas. La crueldad era ejercitada contra el cuerpo de un joven desarmado e indefenso, sometido al dolor y al terror. Y como décadas atrás advirtiera Benjamin, ni los muertos estaban a salvo. El cadáver de Amadeo fue atacado con inscripciones humillantes en brea y con la intención de montar la idea de que había sido un ajuste de cuenta. La policía estaba en pleno conocimiento de su identidad perretista. La idea de que era tupamaro o montonero sólo pueden responder a una intencionalidad explícita de desinformación.

La represión y sus crueles marcas no acabó con los asesinatos, sino que se extendió sobre la sobreviviente al allanamiento, como también al sobreviviente del accidente que pasó a engrosar la lista de desaparecidos/as durante la dictadura. Monona tuvo que atravesar un camino de tormentos que fue común a decenas de miles de personas en Argentina. El mantenerse escondida en medio del terror, perseguida por las fuerzas represivas, con una pareja asesinada, fueron parte de las marcas de lo que se denominó el exilio interno o insilio, aquel que transitaron las personas que no se fueron del país, pero que se tuvieron que esconder en el mismo. Con una particularidad, ella estaba embarazada. Tal como se ha demostrado en un artículo de reciente publicación, los dispositivos represivos tuvieron una dimensión atravesada por el género, cuyas prácticas sistemáticas incluyeron la violencia sexual y la desmaternalización ${ }^{71}$. Como máxima expresión de la incoherencia con el discurso familiarista que decían encarnar, las fuer-

71. L. Rodríguez Agüero (2019).

(C) Baetica. Estudios Historia Moderna y Contemporánea, 40, 2020, 427-455. Facultad de Filosofia y Letras, Universidad de Málaga. Departamento de Historia Moderna y Contemporánea 
zas represivas, que supuestamente veneraban a las madres, en los centros clandestinos las torturaban y amenazaban con quitar la vida a sus hijas/os, a las/os cuales en muchos casos robaron para sustituirles la identidad ${ }^{72}$. Si bien Monona no vivió esta situación, que sí atravesaron otras perretistas mendocinas durante la dictadura, el terror sobre lo que podía pasar con la vida de su beba fue un fantasma que acompañó su embarazo y primeros años de vida de la niña. Un fantasma que no fue producto de su propia imaginación, sino de la perpetración del terror desde la esfera estatal. De hecho, el hospital donde fue a parir se constituyó en su centro clandestino de detención.

Los hechos también permiten analizar la actuación de los sectores subalternos y extraer algunas conclusiones. La inmediata decisión del responsable regional del PRT-ERP respecto de ir a buscar a los compañeros contradice las tesis que difunden la idea de bases mandadas a la muerte por sus direcciones. No tenían posibilidades materiales de montar un operativo de rescate o hacer un trabajo de inteligencia y logística sobre la zona. Simplemente se subieron dos compañeros a un auto y los fueron a buscar, exponiéndose a atravesar el gran despliegue policial. El hecho habla de compañerismo, de solidaridad, del valor de la vida de los compañeros y de lo que se estaba dispuesto a hacer por ella.

En un mismo sentido se inscribe la reacción del estudiantado de la Escuela de Comunicación Colectiva, así como la solidaridad de las/os estudiantes de Arte y Medicina. Es preciso aclarar que esos son los sujetos populares que emergen de modo explícito en la prensa de la época, pero que suele suceder que la participación cotidiana es más amplia y extensa de lo que los diarios reflejan. Sus acciones de lucha, entre asambleas, comunicados, pedidos de hábeas corpus y reuniones con funcionarios, aun conociendo la pertenencia de Amadeo a una organización guerrillera, dan cuenta de una decisión consciente y colectiva, muy distante de la imagen de indiferencia que ha querido imponer la historiografía hegemónica local. Una vez más, el militante perretista Amadeo Sánchez Andía no era un infiltrado en su lugar de estudio. El desmoronamiento de esa imagen permite tener acceso a otra más real e histórica, que fueron las relaciones sociales de solidaridad, cómplices en la lucha e indóciles ante las constantes amenazas.

En síntesis, el análisis de los dos casos reconstruidos, el de enero y el de junio de 1975, dan cuenta de un elevado nivel de respuesta por parte de 
quienes eran compañeras/os de trabajo y estudio de los/a secuestrados/a. Lejos de la supuesta indiferencia de la "gente común" con la que insisten ciertas perspectivas interpretativas del pasado reciente argentino, las evidencias demuestran lo contrario. Sus luchas además deben ser ponderadas teniendo en cuenta el creciente despliegue represivo y la operatividad de comandos parapoliciales. Por lo cual, participar de una movilización, demandar reuniones con las autoridades o ir a los diarios a realizar una denuncia implicaba el riesgo cierto de ser un nuevo blanco para los ataques. Esto no equivale a decir que la sociedad toda fue resistente al golpe de Estado, pero sí permite resquebrajar, agrietar la idea hegemónica de que las grandes mayorías fueron silenciosas o indiferentes. El análisis de los diversos comportamientos frente a los embates represivos y frente al golpe de Estado no debe perder de vista las diferentes posiciones de clase en una sociedad caracterizada por desigualdades de poder.

\section{FUENTES}

\subsection{Entrevistas de elaboración propia}

Entrevista a Abel Bohoslavsky, médico en Córdoba, 18/11/2009, Capital Federal, Argentina.

Entrevista a Vilma Rúpolo, estudiante de Comunicación Colectiva, 25/02/2011, Mendoza, Argentina.

Entrevista a Mirtha "Monona" Ramírez, estudiante de Comunicación Colectiva, 26/02 y 16/04/2011, General Alvear, Mendoza, Argentina.

Entrevista a Luis "Pelado" Ocaña, bancario, miembro de la Comisión Interna del Banco de Previsión Social, 08/04 y 15/04/2011, Mendoza, Argentina.

Entrevista a Rafael Bonino, estudiante de Ciencias Agrarias, 10/09/2020, por videollamada, Argentina.

\subsection{Fuentes periodísticas}

Diario Los Andes

Diario Mendoza

El Combatiente

Estrella Roja

\section{AUDIOVISUALES}

SepúlvedA, Rodrigo y AgüERo, Cecilia (2005), 7746 - Legajo CONADEP, Mendoza. 


\section{BIBLIOGRAFÍA}

AntognazzI, Irma (1997), "La lucha armada en la estrategia política del PRT-ERP (1965-1976)”, Razón y Revolución, 3, Buenos Aires.

Ayles Tortolini, Violeta (2020), "Orígenes del PRT-ERP en Mendoza", Estudios: Centro de Estudios Avanzados, 44. pp. 83-101.

Calveiro, Pilar (2005), Política y/o violencia. Una aproximación a la guerrilla de los años 70, Grupo Editorial Norma, Buenos Aires.

CARAsSaI, Sebastián (2013), Los años setenta de la gente común. La naturalización de la violencia, Siglo XXI, Buenos Aires.

Carnovale, Vera (2011), Los combatientes. Historia del PRT-ERP, Siglo XXI, Buenos Aires.

Cueto, Adolfo; Romano, Aníbal y Sacchero, Pablo (1994), Historia de Mendoza. Desde los primitivos habitantes a nuestros días, Diario Los Andes, Mendoza.

D’Antonio, Débora y Rodríguez Agüero, Laura (2017), "Una lectura de la represión desde los bordes del género", Ponencia en III Jornadas de la Red de Estudios sobre Represión y Violencia Política, Universidad Nacional de La Plata, Buenos Aires.

Lacoste, Pablo (2004), "Utopía y resistencia (1955-1973)”, en A. Roig; P. Lacoste y M. ${ }^{a}$ C. Satlari (comps.), Mendoza a través de su historia, Caviar Bleu, Mendoza, pp. 335-366.

Levín, Florencia (2009), "El pasado reciente entre la historia y la memoria", en VV.AA., La historia reciente como desafio a la investigación y pensamiento en Ciencias Sociales, CAICYT CONICET, Buenos Aires.

Longoni, Ana (2007), "El mandato sacrificial", en I Jornada académica: Partidos armados en la Argentina de los setenta, Universidad Nacional de San Martín.

Micale, Adriana (2004), "Crisis y conflicto (1973-1983)", en A. Roig; P. Lacoste y M. ${ }^{a}$ C. Satlari (comps.), Mendoza a través de su historia, Caviar Bleu, Mendoza, pp. 367-406.

OBERTI, Alejandra (2015), Las revolucionarias. Militancia, vida cotidiana y actividad en los setenta, Edhasa, Buenos Aires.

Rodríguez AgüEro, Laura (2013), Ciclo de protestas, experiencias organizativas y represión paraestatal: Mendoza, 1972-1976, Tesis de Doctorado, Universidad Nacional de La Plata, Facultad de Humanidades y Ciencias de la Educación, Memoria Académica, disponible en: http://www.memoria.fahce. unlp.edu.ar/tesis/te.889/te.889.pdf

Rodríguez AgüEro, Laura (2019), "Las hijas del trueno". Algunas notas sobre el carácter sexuado de la represión en Mendoza (1976)", Páginas, Año 11, 27, pp. XX.

Rodríguez Agüero, Laura; Baraldo, Natalia y Lozano, Pablo (2016), Hacia adentro. La Bancaria Seccional Mendoza. Acuarelas de sus luchas y desaparecidos/ as, La Bancaria, Mendoza. 
Resquebrajamientos de la teoría del consenso social con el Golpe de Estado... 455

Rodríguez Agüero, Laura; Paredes, Héctor Alejandro (2012). “Organizaciones de derecha y conspiración antiallendista en Mendoza, Argentina (1970-1976)”, Revista de Estudios Trasandinos 17, Asociación Chileno Argentina de Estudios Históricos e Integración Cultural, pp. 71-88.

SANTUChO, Julio (2004), Los últimos guevaristas. La guerrilla marxista en la Argentina, Vergara, Buenos Aires.

Seonne, María (1991), Todo o nada. La historia secreta y política del jefe guerrillero Mario Roberto Santucho, Planeta, Buenos Aires. 